\title{
Proposição de Requisitos, Critérios e Métodos de Avaliação de Desempenho de Espaçadores Utilizados em Estrutura de Concreto Armado
}

\author{
Denise Carpena Coitinho Dal Molin \\ João Ricardo Masuero \\ Maria Fernanda Fávero Menna Barreto \\ Ana Paula Maran
}

\section{Introdução}

O tema avaliação de desempenho de materiais, componentes e sistemas não é assunto inédito no Brasil, visto que, desde início da década de 80 , esse tópico vem sendo tratado de forma sistemática por alguns grupos no país (MITIDIERI FILHO et al., 2002). Entretanto, por vezes, tal abordagem se limitou a pesquisas isoladas, executadas por equipes altamente especializadas.

Apesar de haver um certo atraso, comparado ao cenário internacional, constata-se que hoje o conceito de desempenho está disseminado no Brasil (MITIDIERI FILHO et al., 2002), difundido graças aos diversos trabalhos realizados no âmbito acadêmico, que culminaram na primeira norma brasileira de desempenho aplicada a edifícios habitacionais de até 5 pavimentos, a NBR 15575 (ABNT, 2013).

Em 2013, essa mesma norma, que estava suspensa, teve sua abrangência ampliada ao englobar todas as edificaçôes habitacionais, reacendendo 
assim as discussóes acerca da abordagem de desempenho, agora com força de norma que deve ser atendida.

O conceito de desempenho, segundo Spekkink (2005), é aplicável a diferentes níveis de decomposição e agregação de uma construção: à construção em sua forma integral, bem como a seus elementos, componentes e materiais. Para garantir um desempenho adequado às construçóes, é imprescindível que se assegure, principalmente, um desempenho apropriado de seus materiais constituintes. Um desempenho insatisfatório dos materiais componentes é o suficiente para comprometer todo um sistema.

O fracasso na obtenção do cobrimento é, provavelmente, o maior fator influente na corrosão prematura de armaduras (MARSH, 2003), que, por sua vez, é a principal forma de deterioração de estruturas de concreto armado (CLARK et al., 2007). Contudo, a obtenção do cobrimento geralmente não é percebida pelos engenheiros como um problema, logo não lhe é dada prioridade (CLARK et al., 2007). Pesquisas indicam que o cobrimento mínimo projetado não tem sido alcançado em sua totalidade nas obras atuais (CLARK et al., 2007; MENNA BARRETO, 2014; MARAN, 2015).

Um dos maiores problemas relacionado à execução de estruturas de concreto armado é a incapacidade de posicionar a barra de aço com o correto cobrimento de concreto, afetando diretamente o comportamento mecânico e a durabilidade da estrutura (SHAW, 2007), fato que exige açóes corretivas envolvendo reparos caros (MERRETZ, 2010).

A correta execução do cobrimento, com concreto de qualidade, adequadamente curado e compactado, reduz significativamente a quantidade de recursos anualmente gastos, em nível mundial, na manutenção e recuperação de estruturas em concreto armado (MARSH, 2003).

Muitos dos problemas que acarretam um cobrimento insuficiente estão relacionados a falhas no projeto, ao detalhamento ou ao fornecimento de materiais e provavelmente apenas podem ser resolvidos quando abordados em sua origem (MARSH, 2003).

Desta forma, essa questão está diretamente relacionada aos espaçadores, pois eles são responsáveis pelo correto posicionamento do aço, proporcionando assim uma adequada proteção a esse elemento (VAQUERO, 2007).

Espaçadores são essenciais na execução de estruturas de concreto armado e protendido. Por esse motivo, a NBR 14931 (ABNT, 2004) 
recomenda seu uso. Tais dispositivos são amplamente utilizados em grandes quantidades nas construções que adotam essa solução estrutural, que compreende a maioria no país.

Entretanto, a produção e utilização inadequada dos espaçadores têm sido uma das principais causas do mau posicionamento das armaduras [BS 7973-1 (BSI, 2001)]. A inexistência de uma norma brasileira que regulamente a produção e o uso dos espaçadores e, consequentemente, a falta de certificação de qualidade pelo órgão responsável pela fiscalização de produtos contribuem para o agravamento dessa situação.

Este capítulo busca contribuir com o avanço na abordagem de desempenho no Brasil e também com o tema durabilidade das estruturas de concreto armado, com foco na correta obtenção da espessura de cobrimento, por meio da proposição de métodos de avaliação de desempenho de espaçadores, bem como de requisitos e critérios para esses dispositivos. Alguns modelos e marcas disponíveis no mercado brasileiro foram avaliados utilizando os requisitos, critérios e métodos aqui propostos.

\section{Metodologia}

Para avaliação do desempenho de espaçadores plásticos, foram propostos requisitos, critérios e métodos de avaliação. Tais itens estão organizados segundo os requisitos dos espaçadores, apontados pelas pela Norma Britânica BS 7973-1 (BSI, 2001): dimensões, identificação, fixação, estabilidade, capacidade de carga e aplicação.

\subsection{Requisitos e Critérios de Desempenho}

\subsubsection{Dimensionais}

Os requisitos e critérios dimensionais foram estabelecidos com base na Norma Europeia (CEB, 1990) e Norma Britânica BS 7973-1 (BSI, 2001):

a) proporcionar um único valor de cobrimento $(\mathrm{CEB}, 1990)$ ou no máximo dois cobrimentos em um mesmo espaçador, desde que eles estejam claramente identificados no produto [BS 7973-1 (BSI, 2001)]. Assim, evitam-se erros em sua aplicação, visto que a inversão na colocação do espaçador poderia gerar diferença de cobrimento náo facilmente perceptível, conforme exemplificado na Figura 1; 

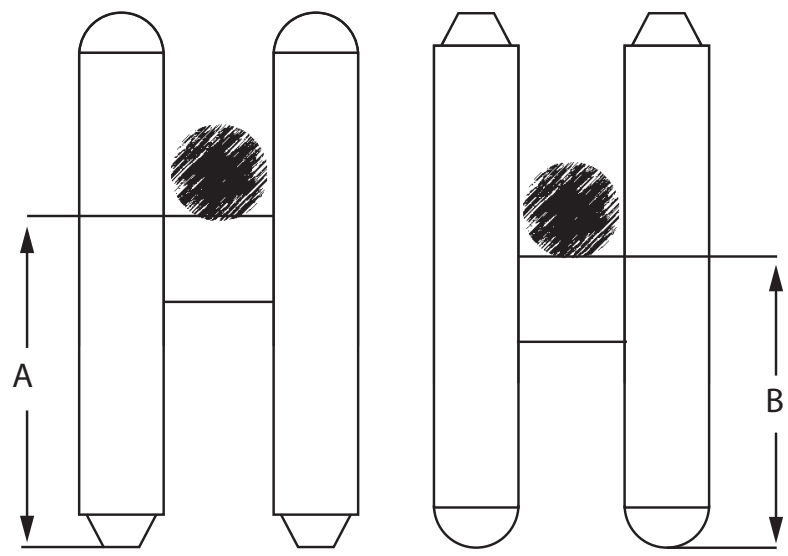

Figura 1. Exemplo de um espaçador com duas possíveis posições de aplicação (VAQUERO, 2007).

b) garantir o cobrimento nominal. Para isso, deve-se saber com precisão a medida do cobrimento especificado pelo fabricante no momento de sua utilizaçáo, com uma tolerância de $\pm 1 \mathrm{~mm}$ para cobrimentos de até 75 $\mathrm{mm}$ e $\pm 2 \mathrm{~mm}$ para cobrimentos maiores [CEB, 1990 e BS 7973-1 (BSI, 2001)]. O espaçador deve possuir essa dimensão, que compreende a base de apoio até o posicionamento final do aço no produto.

\subsubsection{Identificação}

O espaçador deve ser de fácil identificação, mesmo quando misturado com outros de dimensóes diferentes. Ou seja, a dimensão do cobrimento nominal deve estar indicada no próprio produto [BS 7973-1 (BSI, 2001)], conforme mostrado na Figura 2a.
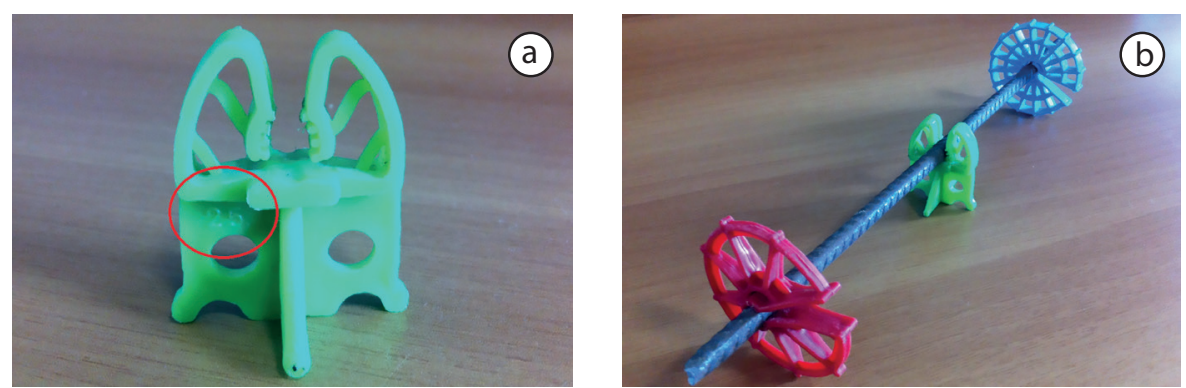

Figura 2. Identificação: a) dimensão do cobrimento no produto; b) cores distintas entre espaçadores. 
Embora nenhuma norma exija outra distinção além da identificação do cobrimento expressa no espaçador, quando se tratar de um mesmo modelo, porém indicado para cobrimentos diferentes, esses produtos devem possuir cores distintas, como indicado na Figura 2b. Dessa forma, evitase que, durante uma concretagem com diversas espessuras de cobrimento, o espaçador especificado se confunda com outros semelhantes, situação ilustrada na Figura 3. O mesmo vale para espaçadores que proporcionam dois cobrimentos diferentes em um único produto. Nesse caso, tal dispositivo deverá possuir cores distintas para cada cobrimento proporcionado, de modo a ser possível a identificação do cobrimento utilizado inclusive à distância.
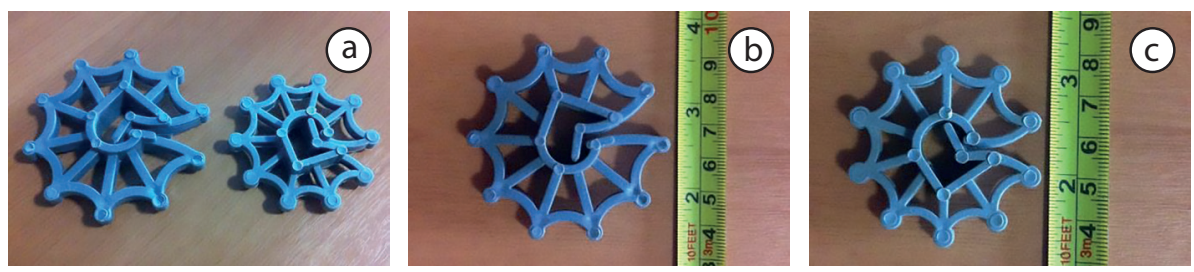

Figura 3. a) Espaçador do mesmo fabricante, do mesmo tipo, e do mesmo modelo, porém com cobrimentos diferentes: b) espaçador para cobrimento de 25 $\mathrm{mm}$; c) espaçador para cobrimento de $20 \mathrm{~mm}$.

Além disso, o fabricante deve estar identificado no produto, seja pelo nome, seja pela logomarca ou pela CNPJ, para fins de rastreabilidade.

\subsubsection{Fixação e Aplicação}

A presença de um item de fixação integrado ao produto é essencial para permitir o acoplamento do espaçador às armaduras, evitando que ele se solte do conjunto, perdendo sua função, conforme mostrado na Figura 4. Tal item não pode ficar a cargo dos responsáveis pela montagem da armação, devido ao risco de náo ser executado.

O item de fixação, quando presente no espaçador, deve ser capaz de prender-se na armadura e resistir ao deslocamento vertical imposto por uma barra de aço com uma carga de 5N \pm 0,1N [CEB, 1990 e BS 7973-1 (BSI, 2001)], conforme Figura 5, no sentido longitudinal da barra, de modo a não permitir que o conjunto se movimente/deslize no espaçador ou vice-versa. 

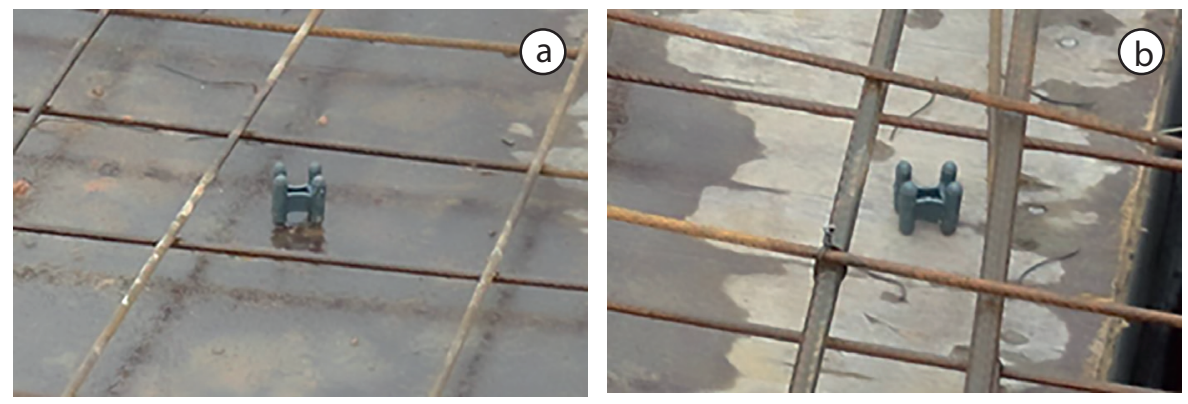

Figura 4. Espaçadores que se soltaram da armadura, não desempenhando mais a sua função.

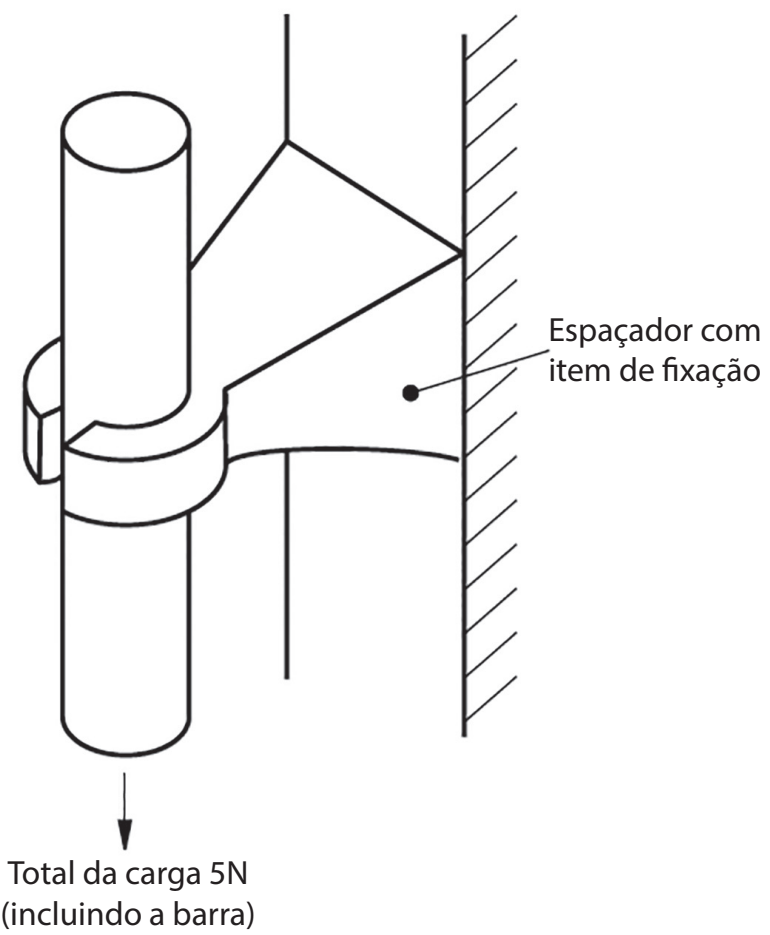

Figura 5. Representação esquemática do ensaio de fixação do espaçador [CEB, 1990 e BS 7973-1 (BSI, 2001)].

Ademais, o item de fixação do espaçador deve proporcionar fácil aplicação às barras de aço. Deste modo, não há necessidade de mão de obra qualificada para seu encaixe. Para tanto, não devem requerer mais de $150 \mathrm{~N}$ 
(força aplicável por qualquer adulto) para sua colocação no maior diâmetro de barra informado pelo fabricante [CEB, 1990 e BS 7973-1 (BSI, 2001)].

\subsubsection{Estabilidade}

O espaçador deve possuir uma estabilidade mínima, de modo que, quando solicitado durante uma concretagem, continue desempenhando seu papel, evitando-se assim problemas, como o tombamento, exemplificado na Figura 6.

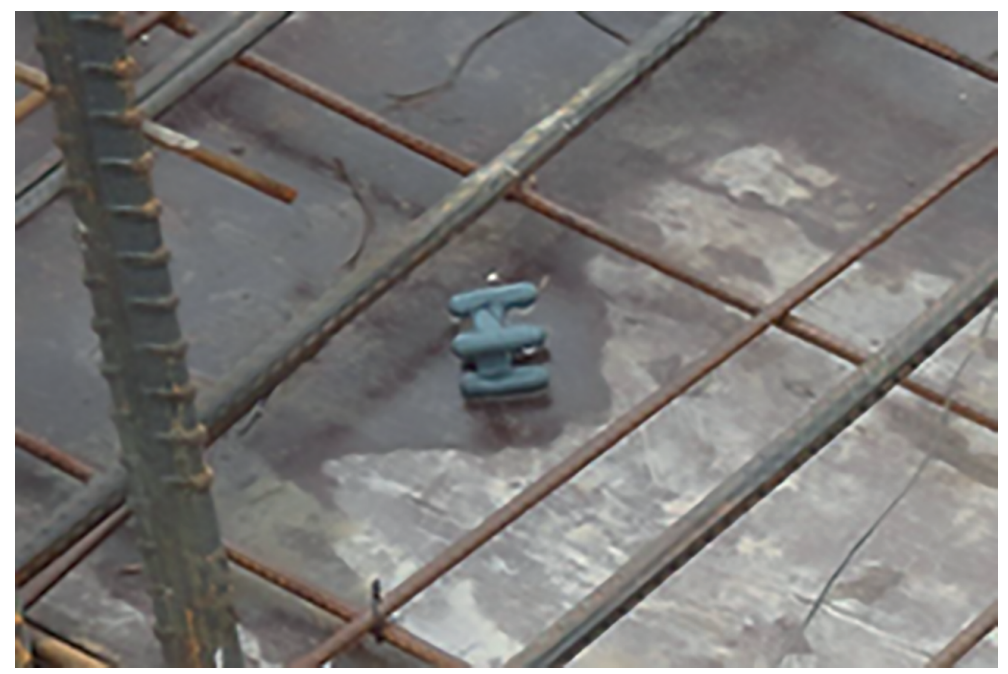

Figura 6. Espaçador tombado durante um concretagem.

A estabilidade é garantida pela existência de um item de fixação e por dimensôes mínimas. De acordo com o Comitê Euro-Internacional do Concreto (CEB, 1990) e a Norma Britânica BS 7973-1 (BSI, 2001), nos espaçadores com fixador integrado, excetuando-se os circulares, a estabilidade é assegurada por um raio de rotação mínimo de $5 \mathrm{~mm}$ do cobrimento proporcionado, medido na superfície de apoio, para o tombamento do espaçador. Espaçadores circulares não requerem um raio mínimo de rotação perpendicular à barra, a estabilidade é fornecida pela largura do apoio central paralelo à barra, que deve ser maior do que a metade do cobrimento fornecido, conforme Figura 7. 
(a)

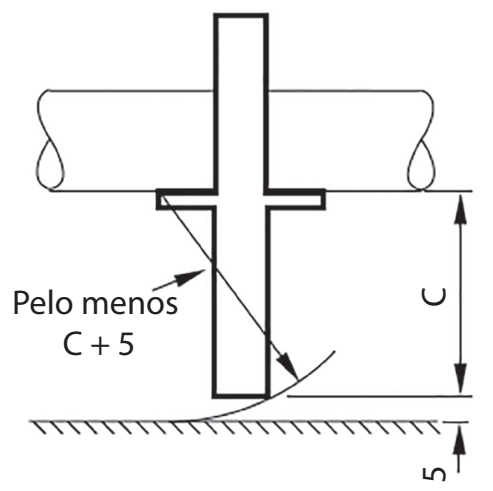

(c)

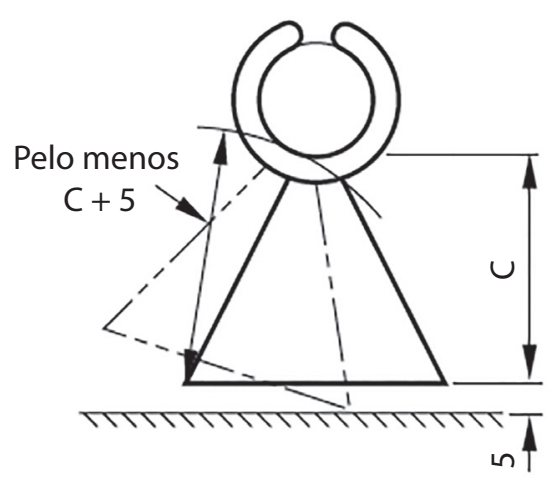

(b)

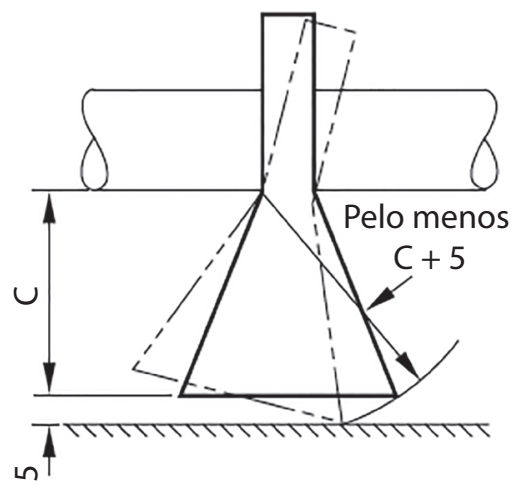

(d)

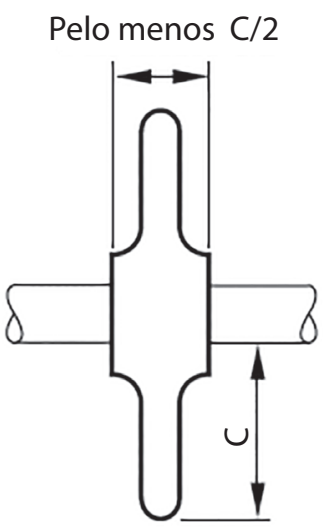

Figura 7. Requisitos geométricos de estabilidade de espaçadores com fixadores integrados [CEB, 1990 e BS 7973-1 (BSI, 2001): a) raio de rotação paralelo à barra de aço; b) raio de rotação paralelo à barra de aço; c) raio de rotação perpendicular à barra de aço; d) largura do apoio central de espaçadores circulares.

\subsubsection{Capacidade de Carga}

O espaçador deve permanecer íntegro durante o processo de concretagem, resistindo ao carregamento imposto - como o peso da armadura, as 
operaçóes de montagem e concretagem, o peso de operários e máquinas, entre outros - sob uma carga mínima estimada de 3,0 kN - máxima força sugerida pelo Comitê Euro-Internacional do Concreto (CEB, 1990) e pela Norma Britânica BS 7973-1 (BSI, 2001) - para espaçadores com grandes solicitaçóes, como os utilizados em lajes e fundo de vigas (cadeirinhas e multiapoio), e uma carga mínima de $0,25 \mathrm{kN}$ (força leve sugerida pelo Comitê Euro-Internacional do Concreto (CEB, 1990) e pela Norma Britânica BS 7973-1 (BSI, 2001) para espaçadores utilizados nas laterais dos elementos, como os circulares. Tais forças devem ser resistidas sob uma deformação linear máxima permanente no sentido do cobrimento de $1 \mathrm{~mm}$ [CEB, 1990 e BS 7973-1 (BSI, 2001)], evitando situações como a retradada pela Figura 8.

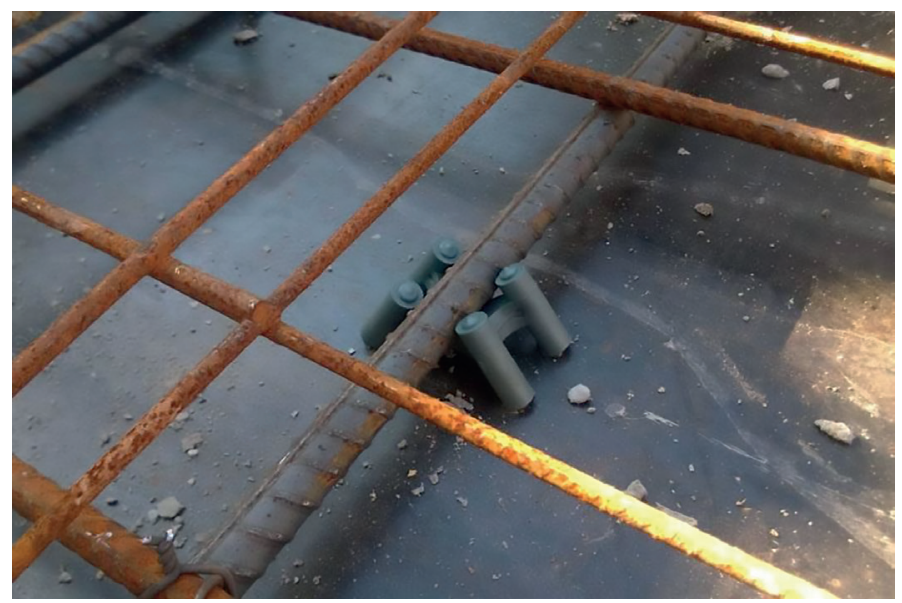

Figura 8. Deformação do espaçador diante da carga em serviço.

\subsection{Métodos de Avaliação de Desempenho}

Após estabelecidos os requisitos e critérios de desempenho, são propostos métodos para sua verificação e avaliação.

\subsubsection{Dos Requisitos Dimensionais}

Apesar das normas estrangeiras não se manifestarem a respeito do modo de avaliação dos requisitos e critérios dimensionais, foram desenvolvidos os métodos a seguir: 
a) o método de avaliação do desempenho do requisito "Proporcionar um único valor de cobrimento ou no máximo dois claramente identificados" consiste em uma inspeção visual e na análise de projeto do produto. $\mathrm{O}$ desempenho é considerado satisfatório quando o espaçador proporcionar apenas um cobrimento ou, no caso de dois cobrimentos em um mesmo espaçador, os valores devem estar claramente identificados no produto;

b) o método de avaliação do desempenho do requisito "Garantir o cobrimento nominal" consiste em uma inspeção dimensional por meio da aplicação de uma barra de aço ao espaçador, que em seguida é medida, com o auxílio de um paquímetro digital com precisão de $0,02 \mathrm{~mm}$, a distância $(\mathrm{C})$ entre a base de apoio e o fundo da barra de aço, conforme a Figura 9, imediatamente antes e depois do espaçador. O desempenho é considerado satisfatório quando o cobrimento proporcionado pelo produto for igual ao especificado pelo fabricante com uma tolerância de $\pm 1 \mathrm{~mm}$ para cobrimentos de até $75 \mathrm{~mm} \mathrm{e} \pm 2 \mathrm{~mm}$ para recobrimentos maiores.
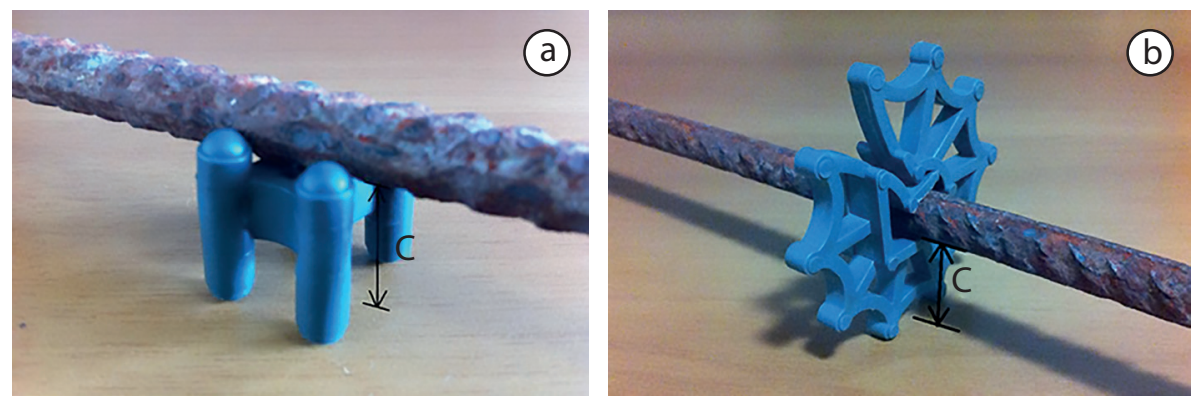

Figura 9. Método de avaliação do desempenho físico: a) em espaçadores tipo cadeirinha; b) em espaçadores circulares.

\subsubsection{Do Requisito Identificação}

O método de avaliação do desempenho desse requisito consiste em uma inspeção técnica do produto. Caso ele possua a informação de cobrimento nominal, cor diferenciada para espaçadores de mesmo modelo, cores distintas para cada cobrimento diferente proporcionado em um mesmo espaçador e identificação do fabricante, ele é considerado satisfatório, caso contrário é considerado insatisfatório. 


\subsubsection{Do Requisito Fixação e Aplicação}

O método de avaliação do desempenho do requisito de fixação consiste em uma inspeção técnica e análise do projeto do produto, de forma que o espaçador deve apresentar um item de fixação integrado a ele. Se o produto não possuir algum tipo de fixação integrado, automaticamente é considerado insatisfatório.

Entretanto, se o produto apresentar o item de fixação, este deve ser capaz de fixar-se na armadura e resistir ao deslocamento vertical imposto por uma barra de aço com uma carga de $5 \mathrm{~N} \pm$ 0,1N [CEB, 1990 e BS 79731 (BSI, 2001)], conforme Figura 5. O método de avaliação tem como base o ensaio proposto pelo CEB (1990) e a Norma Britânica BS 7973-1 (BSI, 2001), e a armadura utilizada para o ensaio possui o menor diâmetro especificado pelo fabricante como adequado em relação aos espaçadores. Caso não seja informado o menor diâmetro aplicável, o ensaio será executado com uma barra de $5 \mathrm{~mm}$ de diâmetro. Será considerado satisfatório o espaçador que impedir o deslizamento da barra aplicada. Em caso de deslizamento, o espaçador será considerado insatisfatório. Esse parâmetro não contempla tolerâncias.
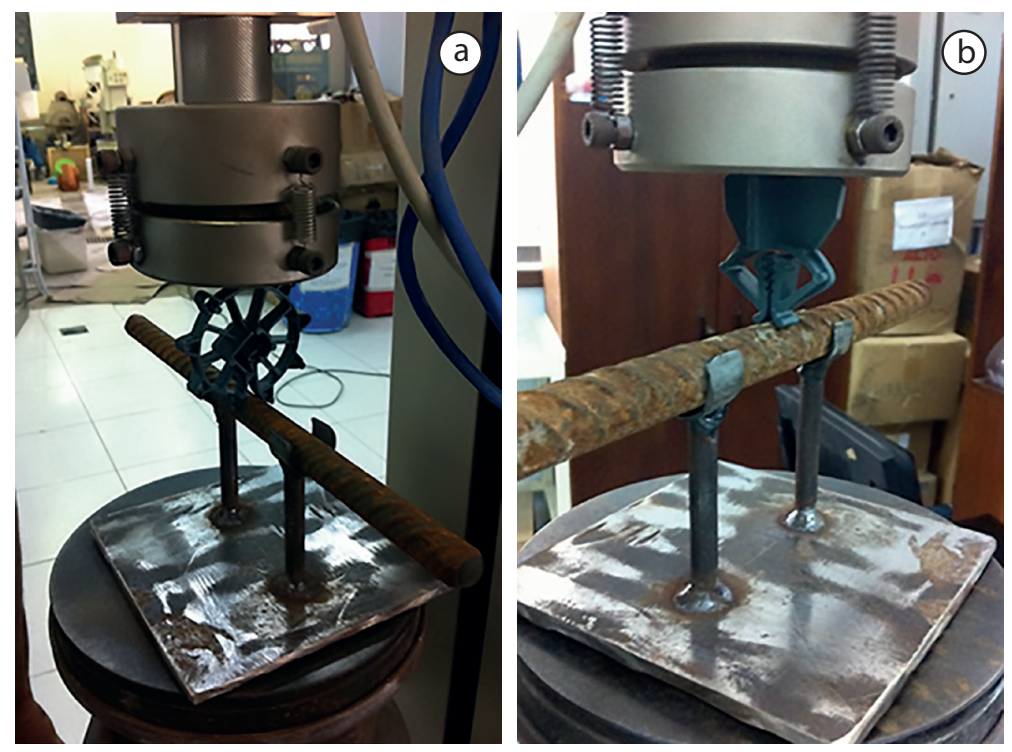

Figura 10. Ensaio de aplicação do espaçador à barra de aço: a) em espaçadores circulares; b) em espaçadores cadeirinha. 
Além de ter um item de fixação, que deve impedir o deslocamento da armadura, o espaçador também tem que ser facilmente aplicável às barras de aço. $\mathrm{O}$ método de avaliação do desempenho desse requisito consiste em ensaio laboratorial, no qual se apoia o espaçador sobre o maior diâmetro de barra recomendado pelo fabricante. Em seguida, o conjunto é inserido em uma prensa, conforme Figura 10, e a carga é aplicada até o encaixe total do espaçador à barra de aço. $\mathrm{O}$ produto é considerado satisfatório quando não exigir mais de $0,15 \mathrm{kN}$ de força para sua completa aplicação.

Apesar do CEB (1990) e a Norma Britânica BS 7973-1 (BSI, 2001) não indicarem um procedimento específico para análise desse requisito, o ensaio proposto foi concebido a fim de se ter um método de avaliação para esse item. Desta forma, desenvolveu-se o dispositivo especificado na Figura 11, no qual é possível a troca de diferentes barras de aço para execução do ensaio.

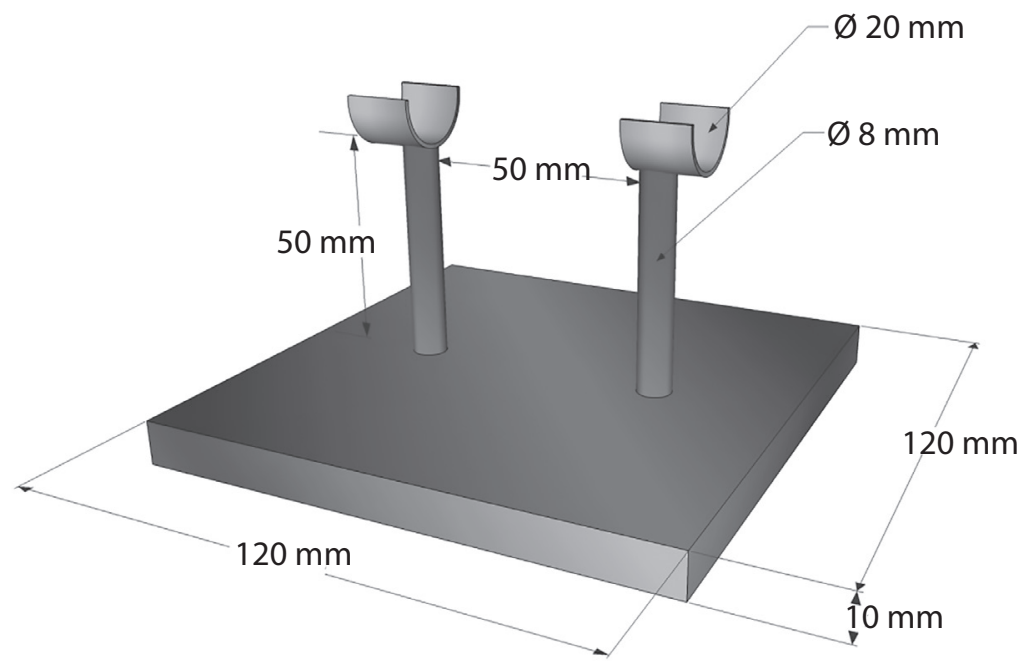

Figura 11. Dispositivos desenvolvidos para avaliação de desempenho do requisito fixação.

\subsubsection{Do Requisito Estabilidade}

O método de avaliação desse requisito de desempenho consiste na medição das dimensôes do espaçador, utilizando-se um paquímetro digital com precisão de 0,02 mm, exemplificado na Figura 12, levando em conta as 
especificaçóes do Comitê Euro-Internacional do Concreto (CEB, 1990) e da Norma Britânica BS 7973-1 (BSI, 2001).
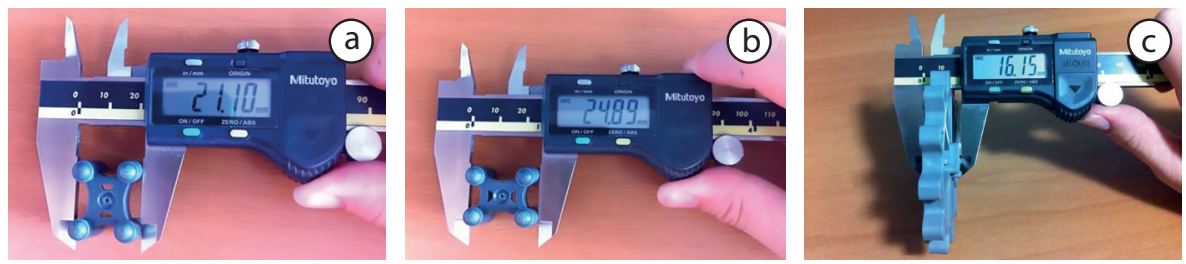

Figura 12. Medição das dimensões dos espaçadores tipo cadeirinha: a) medida paralela ao posicionamento da barra; b) medida perpendicular ao posicionamento da barra; c) medida do centro de apoio do espaçador circular.

Em espaçadores com item de fixação integrado, excetuando-se os circulares, a estabilidade é garantida quando assegurado um raio de rotação mínimo de $5 \mathrm{~mm}$ maior do que o cobrimento fornecido pelo produto, para tombamento sobre a superfície de apoio. Esse raio de rotação deve existir nas dimensóes do espaçador paralelas e perpendiculares à armadura ao qual é aplicado, conforme Figura 7 (a, b, c).

Espaçadores circulares não necessitam de raio mínimo de rotação, pois sua estabilidade é fornecida pela largura do apoio central, que deve ser maior do que metade do cobrimento fornecido, conforme exemplificado na Figura $7 d$.

O desempenho é considerado satisfatório quando as medidas atenderem aos valores especificados. Espaçadores que não possuírem item de fixação ou não atenderem aos parâmetros e critérios de desempenho descritos serão considerados insatisfatórios.

\subsubsection{Do Requisito Capacidade de Carga}

A avaliação do requisito capacidade de carga é uma adaptação do método proposto pelo CEB (1990) e Norma Britânica BS 7973-1 (BSI, 2001), que consiste em um ensaio laboratorial.

Para possibilitar a realização do ensaio, foi desenvolvido um dispositivo, apresentado na Figura 11, no qual se aplica um espaçador na barra de aço de $8 \mathrm{~mm}$ do dispositivo, como mostra a Figura 13. Em seguida, insere-se o conjunto (dispositivo + espaçador) em uma prensa e aplica-se força até a capacidade de carga requerida do espaçador, conforme Tabela 1. 

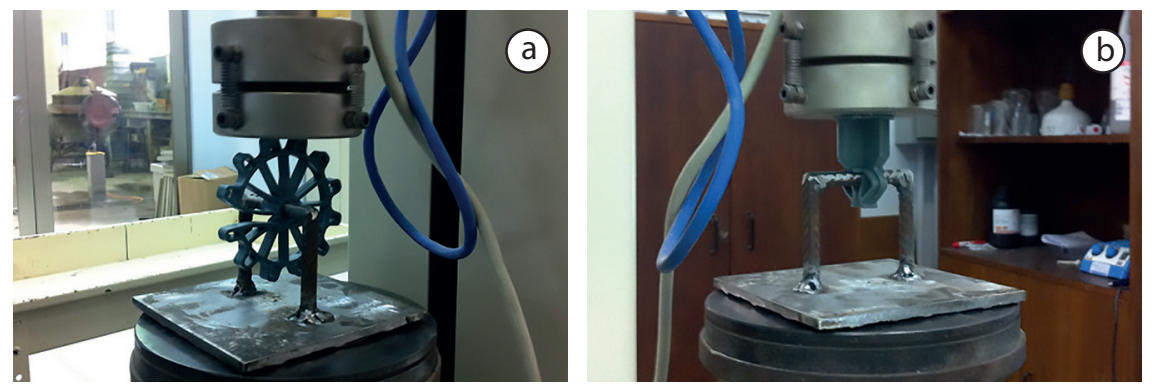

Figura 13. Ensaio de capacidade de carga: a) em espaçadores circulares; b) em espaçadores cadeirinha.

Tabela 1. Parâmetros para o valor da carga máxima aplicada no ensaio do método de avaliação do requisito capacidade de carga.

\begin{tabular}{lcc}
\multicolumn{1}{c}{ Espaçador } & Solicitação & Capacidade de carga \\
\hline Cadeirinha e Multiapoio & Pesada & $3,0 \mathrm{kN}$ \\
\hline Circular & Leve & $0,25 \mathrm{kN}$ \\
\hline
\end{tabular}

Fonte: CEB, 1990 e BS 7973-1 (BSI, 2001).

Ao atingir a capacidade de carga ou o rompimento do espaçador, retira-se o conjunto da prensa e verifica-se a deformação linear permanente no sentido do cobrimento, o qual não pode ser superior a $1 \mathrm{~mm}$.

Caso um espaçador possibilitar dois cobrimentos diferentes, ele deverá ser testado na posição mais desfavorável, ou seja, avaliado no maior cobrimento proporcionado. Atendendo aos critérios de desempenho estabelecidos, os espaçadores serão considerados satisfatórios, caso contrário, serão considerados insatisfatórios.

Embora o CEB (1990) e a Norma Britânica BS 7973-1 (BSI, 2001) possuam um método diferente para essa avaliação (Figura 14), o ensaio proposto acima foi concebido com a finalidade de se obter gráficos gerados com base no comportamento do material prensado, no que diz respeito à força e à deformação desse elemento. 


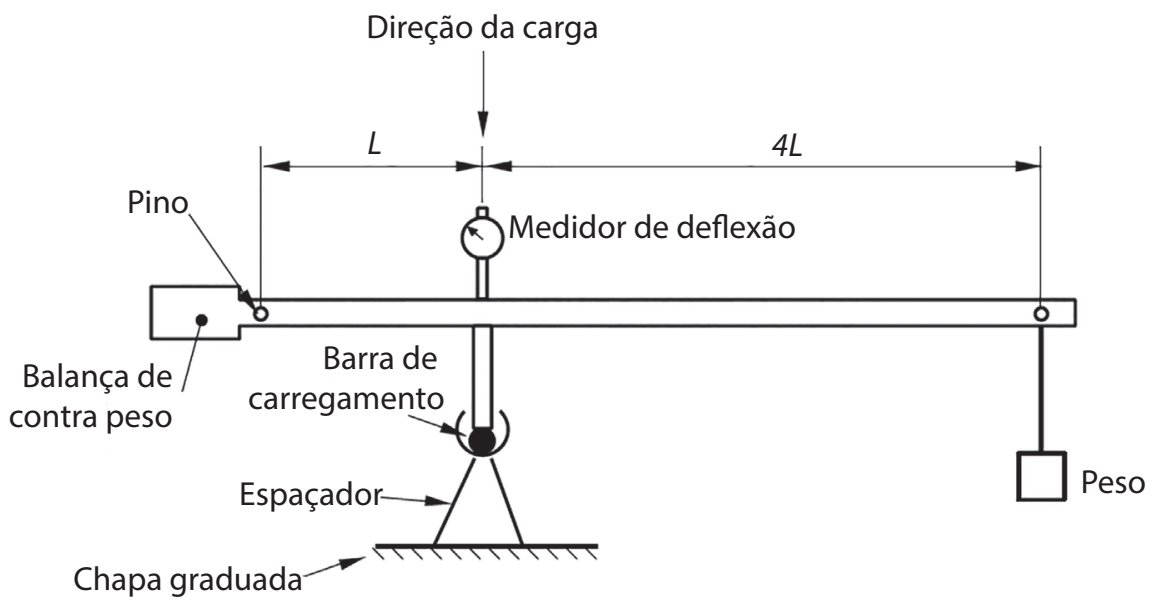

Figura 14. Aparato para teste de capacidade de carga [CEB, 1990 e BS 7973-1 (BSI, 2001)].

\subsection{Resumo dos Requisitos, Critérios e Avaliação de Desempenho}

\begin{tabular}{|c|c|c|c|}
\hline & Requisito & Critério & Método de avaliação \\
\hline \multirow[t]{2}{*}{ Dimensionais } & $\begin{array}{l}\text { a) Proporcionar } \\
\text { um único } \\
\text { cobrimento } \\
\text { ou no } \\
\text { máximo dois } \\
\text { cobrimentos } \\
\text { claramente } \\
\text { identificáveis. }\end{array}$ & $\begin{array}{c}\text { As dimensões } \\
\text { proporcionadas } \\
\text { devem ser claramente } \\
\text { identificáveis no produto. }\end{array}$ & $\begin{array}{l}\text { Verificar, por meio de } \\
\text { uma inspeção visual e } \\
\text { de análise de projeto do } \\
\text { produto, a quantidade de } \\
\text { diferentes cobrimentos } \\
\text { proporcionados. }\end{array}$ \\
\hline & $\begin{array}{l}\text { b) Garantir o } \\
\text { cobrimento } \\
\text { nominal } \\
\text { indicado. }\end{array}$ & $\begin{array}{l}\text { Possuir a medida do } \\
\text { cobrimento especificado } \\
\text { pelo fabricante, com } \\
\text { tolerância de } \pm 1 \mathrm{~mm} \\
\text { para cobrimentos até } \\
75 \mathrm{~mm} \text { e } \pm 2 \mathrm{~mm} \text { para } \\
\text { cobrimentos maiores. }\end{array}$ & $\begin{array}{c}\text { Aplicar uma barra de aço ao } \\
\text { espaçador e medir, com o } \\
\text { auxílio de um paquímetro } \\
\text { digital, o cobrimento } \\
\text { proporcionado. }\end{array}$ \\
\hline
\end{tabular}


Continuação.

\begin{tabular}{|c|c|c|c|}
\hline & Requisito & Critério & Método de avaliação \\
\hline Identificação & $\begin{array}{c}\text { Possuir fácil } \\
\text { identificação, } \\
\text { mesmo } \\
\text { quando } \\
\text { misturado. }\end{array}$ & $\begin{array}{c}\text { A dimensão do } \\
\text { cobrimento nominal } \\
\text { e a identificação do } \\
\text { fabricante devem estar } \\
\text { contidos no produto. } \\
\text { Espaçadores de mesmo } \\
\text { modelo e de cobrimentos } \\
\text { diferentes, assim como } \\
\text { espaçadores com } 2 \\
\text { cobrimentos, devem } \\
\text { possuir cores distintas. }\end{array}$ & $\begin{array}{l}\text { Conferir a existência do } \\
\text { cobrimento nominal } \\
\text { e a identificação do } \\
\text { fabricante no próprio } \\
\text { produto. Verificar se existe } \\
\text { diferenciação de cores entre } \\
\text { um mesmo modelo e se o } \\
\text { espaçador que proporciona } \\
\text { dois cobrimentos em um } \\
\text { mesmo produto possui } \\
\text { cores diferentes conforme o } \\
\text { cobrimento utilizado. }\end{array}$ \\
\hline \multirow{2}{*}{$\begin{array}{l}\text { Fixação e } \\
\text { aplicação }\end{array}$} & $\begin{array}{c}\text { Possuir } \\
\text { capacidade de } \\
\text { fixar-se e não } \\
\text { se deslocar na } \\
\text { armadura. }\end{array}$ & $\begin{array}{c}\text { Possuir item de fixação } \\
\text { capaz de resistir ao } \\
\text { deslocamento proposto } \\
\text { por uma carga de } 5 \mathrm{~N} \pm \\
0,1 \mathrm{~N} \text {, aplicado na direção } \\
\text { do eixo longitudinal } \\
\text { da armadura à barra } \\
\text { de menor diâmetro } \\
\text { informado pelo } \\
\text { fabricante. }\end{array}$ & $\begin{array}{l}\text { Aplicar ao espaçador uma } \\
\text { barra de aço de menor } \\
\text { diâmetro informado pelo } \\
\text { fornecedor com uma carga } \\
\text { total de } 5 \mathrm{~N} \text { na direção do } \\
\text { eixo da armadura e verificar } \\
\text { se há o deslocamento da } \\
\text { barra. }\end{array}$ \\
\hline & $\begin{array}{l}\text { Ser facilmente } \\
\text { aplicável às } \\
\text { barras de aço. }\end{array}$ & $\begin{array}{l}\text { Não devem requerer } \\
\text { mais de } 0,15 \mathrm{kN} \\
\text { para a aplicação no } \\
\text { maior diâmetro de } \\
\text { barra informado pelo } \\
\text { fabricante. }\end{array}$ & $\begin{array}{l}\text { Apoiar o espaçador } \\
\text { no maior diâmetro } \\
\text { recomendado pelo } \\
\text { fabricante. Em seguida, } \\
\text { posicioná-lo sobre o } \\
\text { dispositivo específico } \\
\text { para o ensaio e inserir o } \\
\text { conjunto em uma prensa. } \\
\text { Aplicar força constante } \\
\text { até o completo encaixe do } \\
\text { espaçador à barra. }\end{array}$ \\
\hline Estabilidade & $\begin{array}{c}\text { Possuir } \\
\text { estabilidade e } \\
\text { não tombar. }\end{array}$ & $\begin{array}{l}\text { Para cadeirinhas e } \\
\text { multiapoio: assegurar } \\
\text { um raio de rotação de, } \\
\text { pelo menos, o valor de } \\
\text { cobrimento mais } 5 \mathrm{~mm} ; \\
\text { Para circulares: o centro } \\
\text { de apoio deve possui } \\
\text { espessura superior a } 0,5 \\
\text { do valor de cobrimento } \\
\text { indicado. }\end{array}$ & $\begin{array}{l}\text { Para cadeirinhas e } \\
\text { multiapoio: com um } \\
\text { paquímetro digital, medir } \\
\text { o raio mínimo de rotação } \\
\text { paralelo e perpendicular à } \\
\text { aplicação da barra de aço. } \\
\text { Para circulares: com um } \\
\text { paquímetro digital, medir } \\
\text { a espessura do centro de } \\
\text { apoio do espaçador. }\end{array}$ \\
\hline
\end{tabular}


Continuação.

\begin{tabular}{|c|c|c|c|}
\hline & Requisito & Critério & Método de avaliação \\
\hline $\begin{array}{c}\text { Capacidade } \\
\text { de Carga }\end{array}$ & $\begin{array}{l}\text { Permanecer } \\
\text { íntegro, } \\
\text { resistindo ao } \\
\text { carregamento } \\
\text { imposto e } \\
\text { deformação } \\
\text { máxima } \\
\text { permitida. }\end{array}$ & $\begin{array}{c}\text { Para cadeirinhas e } \\
\text { multiapoio: resistir a uma } \\
\text { carga mínima de } 3 \mathrm{kN} ; \\
\text { Para circulares: resistir } \\
\text { a uma carga mínima de } \\
0,25 \mathrm{kN} ; \\
\text { Resistir ao carregamento } \\
\text { mínimo com uma } \\
\text { deformação linear } \\
\text { máxima de } 1 \mathrm{~mm} \text {. }\end{array}$ & $\begin{array}{c}\text { Aplicar o espaçador no } \\
\text { dispositivo específico para } \\
\text { o ensaio e inserir o conjunto } \\
\text { em uma prensa. Aplicar } \\
\text { força com velocidade de } \\
\text { carregamento constante } \\
\text { até a capacidade de carga } \\
\text { requerida e, em seguida, } \\
\text { medir a deformação linear } \\
\text { permanente com um } \\
\text { paquímetro digital. }\end{array}$ \\
\hline
\end{tabular}

\subsection{Validação dos Métodos de Avaliação do Desempenho dos Espaçadores}

Para validar os métodos de avaliaçáo propostos, foram ensaiados 18 modelos de espaçadores de 5 fabricantes distintos (A, B, C, D e E), conforme Figura 15, Figura 16, Figura 17, Figura 18 e Figura 19, e mais 10 modelos de fornecedores não identificados $(\mathrm{X})$, segundo mostra a Figura 20. Todos esses espaçadores foram obtidos em obras correntes e consistem em: 10 modelos de espaçadores no formato cadeirinha, 13 circulares e 5 multiapoio.

Seguindo critérios do Comitê Euro-Internacional do Concreto (CEB, 1990), ao menos 10 unidades de cada modelo específico foram testadas de acordo com a avaliação proposta e no mínimo $90 \%$ das unidades deveriam satisfazer os requisitos propostos.
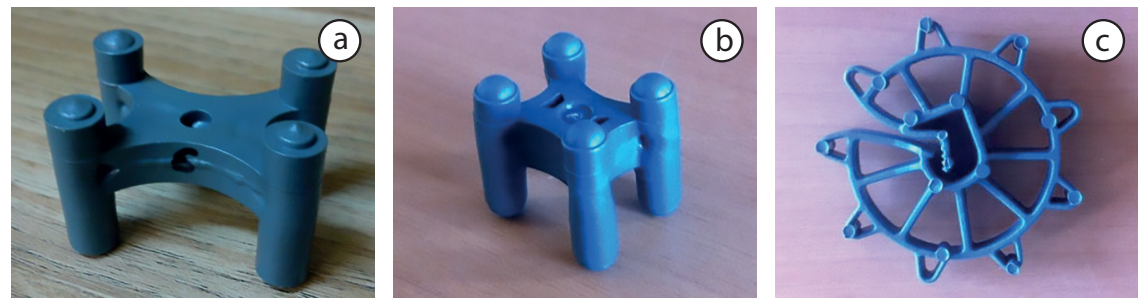

Figura 15. Fabricante $\mathrm{A}$ : a) modelo $\mathrm{A} 1$; b) modelo $\mathrm{A} 2$; c) modelo $\mathrm{A} 3$. 
Avaliação de Desempenho de Tecnologias Construtivas Inovadoras:

Conforto Ambiental, Durabilidade e Pós-Ocupação
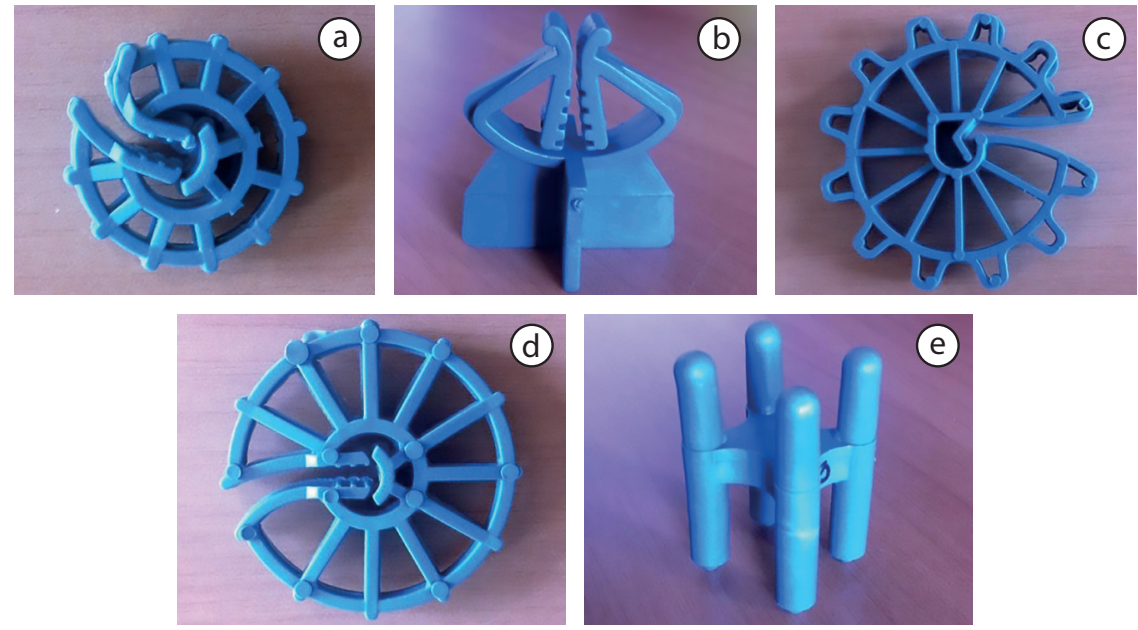

Figura 16. Fabricante $B$ : a) modelo $B 1$; b) modelo $B 2$; c) modelo B3; d) modelo B4; e) modelo B5.
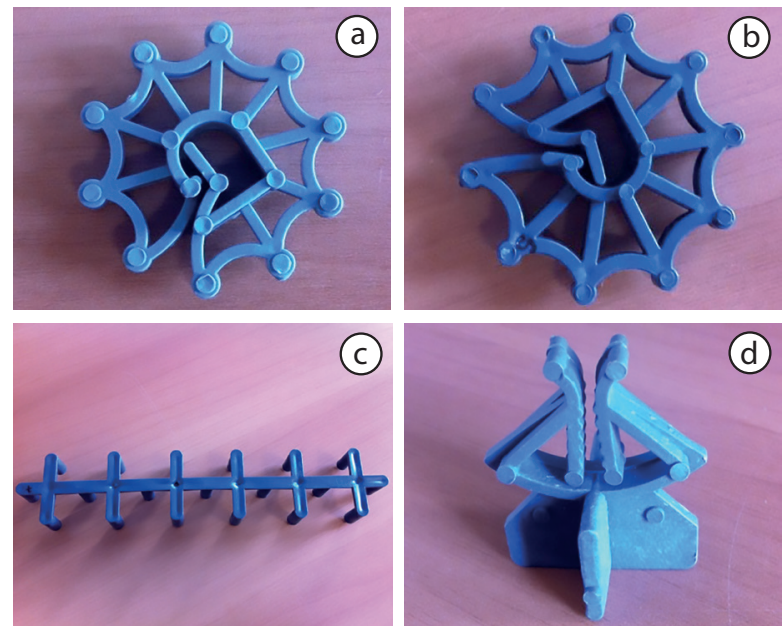

Figura 17. Fabricante $\mathrm{C}$ : a) modelo $\mathrm{C} 1$; b) modelo $\mathrm{C} 2$; c) modelo $\mathrm{C} 3$; d) modelo C4.
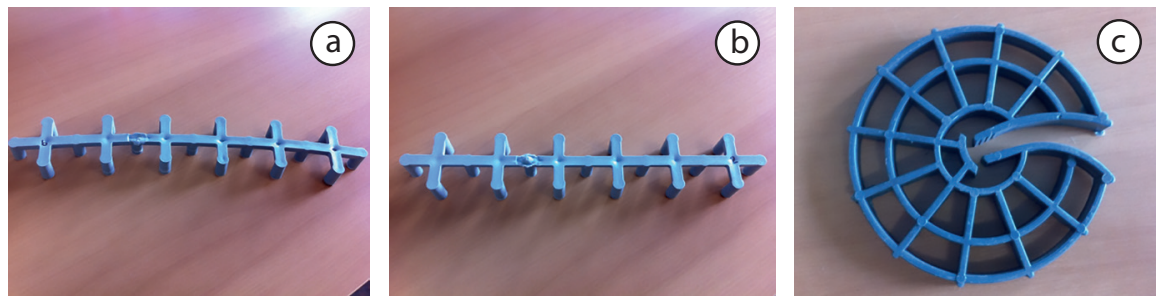

Figura 18. Fabricante D: a) modelo D1; b) modelo D2; c) modelo D3. 

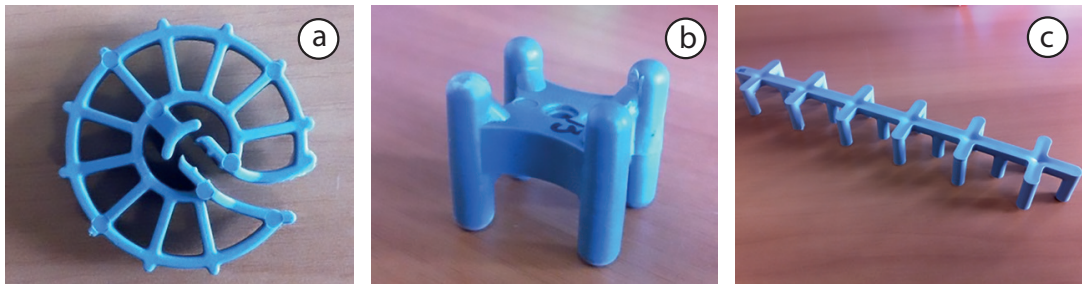

Figura 19. Fabricante $\mathrm{E}$ : a) modelo $\mathrm{E} 1$; b) modelo E2; c) modelo E3.

Sempre que uma amostra (de no mínimo 10 unidades do produto) não conseguir atender aos requisitos especificados anteriormente, todo o lote de espaçadores é rejeitado e considerado insatisfatório.
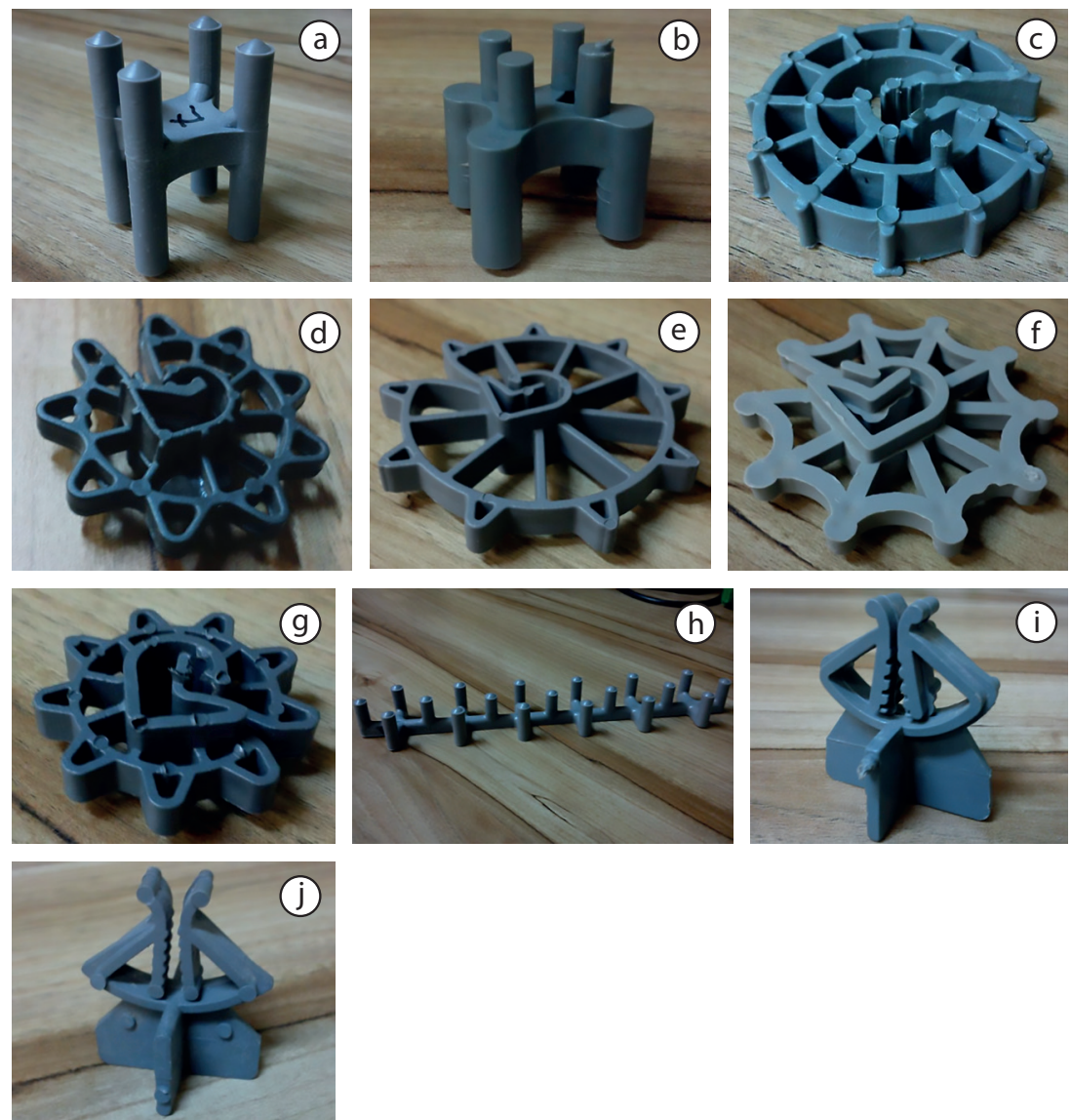

Figura 20. Fabricantes desconhecidos: a) modelo $X 1$; b) modelo $X 2$; c) modelo X3; d) modelo X4; e) modelo X5; f) modelo X6; g) modelo X7; h) modelo X8; i) modelo $\mathrm{X} 9$; i) modelo X10. 


\section{Apresentação e Análise de Resultados}

A seguir, são apresentados e discutidos os resultados obtidos, os quais foram separados por requisitos, tipos de espaçadores e fabricantes.

\subsection{Por Requisitos}

\subsubsection{Dimensionais}

Os modelos A1, A2, B5, E2 e X1 não satisfizeram o primeiro requisito dimensional (proporcionar um único cobrimento ou no máximo dois cobrimentos claramente identificáveis). Entretanto, todas as cadeirinhas foram aprovadas na avaliação do segundo requisito dimensional (garantir o cobrimento nominal indicado).

Para os espaçadores circulares, todos os modelos foram aprovados no primeiro requisito dimensional (proporcionar um único cobrimento ou no máximo dois cobrimentos claramente identificáveis). Já no segundo requisito (garantir o cobrimento nominal indicado), apenas os modelos A3, B3, B4, D3 e E1 se mostraram satisfatórios.

No que concerne aos espaçadores do formato multiapoio, para o primeiro requisito dimensional (proporcionar um único cobrimento ou no máximo dois cobrimentos claramente identificáveis), todos os modelos mostraram-se satisfatórios. Entretanto, na avaliação do segundo requisito dimensional (garantir o cobrimento nominal indicado), apenas o modelo D1 e D2 foram reprovados e, consequentemente, considerados insatisfatórios.

Desta maneira, dos 28 modelos de espaçadores avaliados, 13 foram aprovados em todos os requisitos dimensionais (A3, B2, B3, B4, C3, C4, D3, E1, E3, X2, X8, X9, X10), de forma que 15 foram considerados insatisfatórios em pelo menos uma avaliação desse requisito.

\subsubsection{Identificação}

Ao se avaliar o requisito de identificação, nenhum modelo avaliado apresentou o cobrimento nominal e informaçóes do fabricante especificados no produto. 
No que diz respeito à diferença de cores em um espaçador que proporciona dois cobrimentos, nenhum dos fabricantes identificados (Fabricante A, B, C, D e E) apresentou essa distinção entre seus modelos. Já para os fabricantes náo identificados (fabricantes desconhecidos), não pode afirmar o mesmo, visto que o desconhecimento do produtor impede a rastreabilidade dos produtos de igual modelo.

Apesar de nenhum modelo avaliado satisfazer esse requisito, conforme mostrado na Figura 21, existem espaçadores que atendem a esse critério. Entretanto, eles não foram avaliados devido ao fato de não haver amostras suficientes para avaliação.
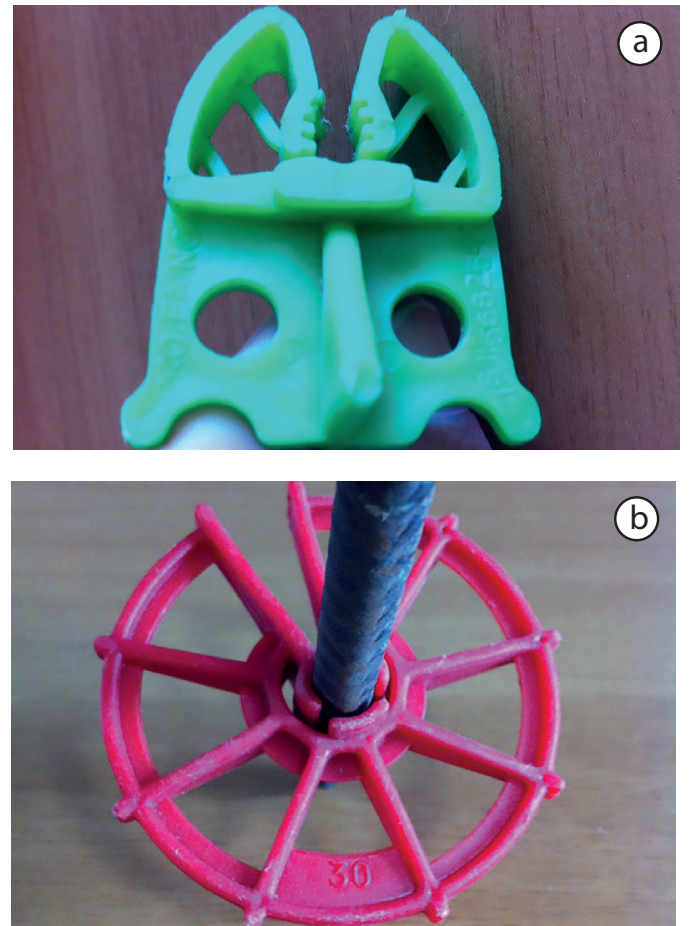

Figura 21. Espaçadores que satisfazem o requisito identificação. 


\subsubsection{Fixação e Aplicação}

Como não existia, em todos os modelos avaliados, a especificação do fabricante em relação ao diâmetro mínimo de armadura para o qual os espaçadores são adequados, adotou-se o menor diâmetro permitido para estribos, ou seja, $5 \mathrm{~mm}$, segundo a NBR 6118 (ABNT, 2014).

Avaliando-se o requisito fixação, quanto ao modelo cadeirinha, embora os modelos B2, C4, X9 e X10 apresentarem item de fixação, ocorreu o deslizamento da barra de aço, fato que os reprovou no segundo método de avaliação proposto.

Quanto aos modelos circulares, os modelos D3 e X3 foram considerados insatisfatórios, pois não impediram o deslocamento da armadura.

Os espaçadores do formato multiapoio foram reprovados. O desempenho insatisfatório ocorreu automaticamente, por não possuírem item de fixaçãa.

No geral, dos 28 modelos avaliados nesse requisito, apenas 17 modelos possuíam item de fixação. Desses, somente 11 (A3, B1, B3, B4, C1, C2, E1, X4, X5, X6 e X7) se mostraram satisfatórios.

Para o requisito aplicação, aqueles que não apresentaram item de fixação, como os modelos A1, A2, B5, C3, D1, D2, E2, E3, X1, X1, X8, não foram ensaiados.

Diferentemente dos modelos de espaçadores de fabricantes identificados, os modelos que possuem fabricantes desconhecidos foram avaliados segundo um método alternativo, pois eles não continham a informação do maior diâmetro recomendado para suas respectivas aplicaçóes. Tal método consistiu em tentativa e erro, no qual o espaçador é aplicado, desde os diâmetros menores até os maiores, progressivamente, até o produto não conseguir ser encaixado com a força máxima requerida.

A avaliação dos modelos cadeirinha mostrou que somente os modelos B2 e C4 são insatisfatórios.

Já com relação aos espaçadores circulares, os modelos A3, B3, C1, C2 foram reprovados e assim considerados insatisfatórios. 


\subsubsection{Estabilidade}

Para o requisito estabilidade, em relação aos resultados das avaliaçóes dos espaçadores de formato cadeirinha, nenhum modelo foi aprovado segundo o método proposto.

Apesar dos espaçadores circulares apresentarem item de fixação, cuja existência é imprescindível para proporcionar estabilidade, somente os modelos A3, B1, C1, E1, X4, X5, X6 e X7 comprovaram desempenho satisfatório na avaliação proposta. Os demais modelos foram reprovados.

Os espaçadores no formato multiapoio não foram avaliados, devido ao fato de não apresentarem item de fixação, tendo seu desempenho reprovado automaticamente.

De modo geral, obtiveram-se 8 modelos satisfatórios e 20 modelos insatisfatórios, conforme método de avaliação proposto.

\subsubsection{Capacidade de Carga}

Avaliação desse requisito analisa duas variáveis: deformação linear máxima permanente e capacidade de carga resistida.

Para os modelos de formato cadeirinha, nota-se que, dos 10 modelos avaliados, apenas 2 (B2 e X9) comprovaram desempenho satisfatório nesse requisito, enquanto o restante foi considerado insatisfatório.

Embora a maioria dos modelos de espaçadores circulares tenha resistido à carga mínima exigida, muitos obtiveram deformação linear permanente superior à máxima permitida. Portanto, somente os modelos C1 e X6 apresentaram deformação linear permanente inferior a $1 \mathrm{~mm}$ e foram aprovados, apresentando desempenho satisfatório.

Nenhum modelo de formato multiapoio foi aprovado segundo o método de avaliação proposto. De todos os formatos, esse foi o que mais apresentou variabilidade na carga resistida. Tal ocorrência se justifica pela diversidade de posiçóes permitidas para sua aplicação, uma vez que esse modelo de espaçador pode ser posicionado perpendicular, paralelo, ou diagonal à barra.

No geral, dos 28 modelos de espaçadores avaliados nesse requisito, 4 (B2, X9, C1 e X6) apresentaram desempenho satisfatório e 24 apresentaram desempenho insatisfatório segundo o método de avaliação estabelecido. 
Avaliação de Desempenho de Tecnologias Construtivas Inovadoras:

Conforto Ambiental, Durabilidade e Pós-Ocupação

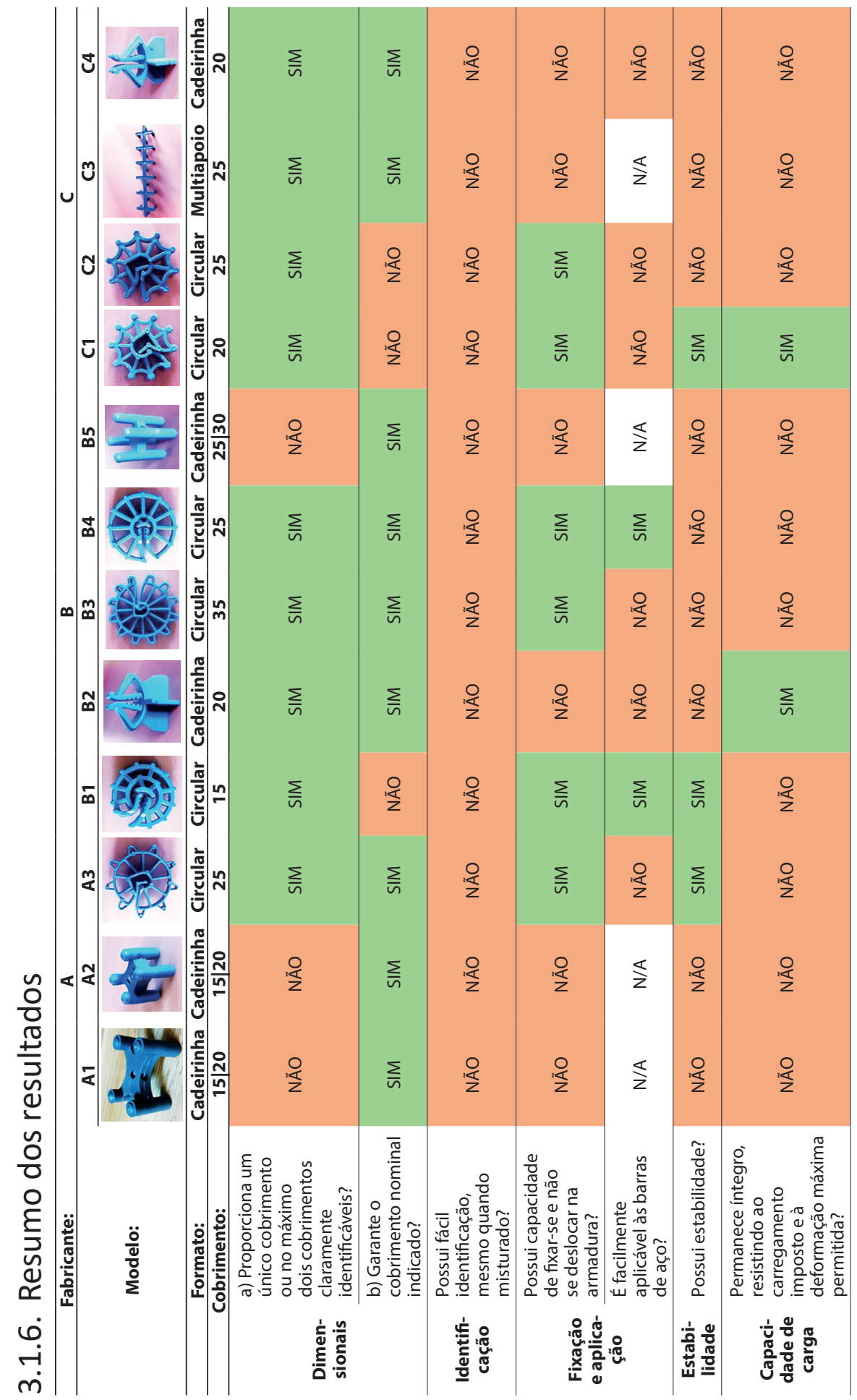




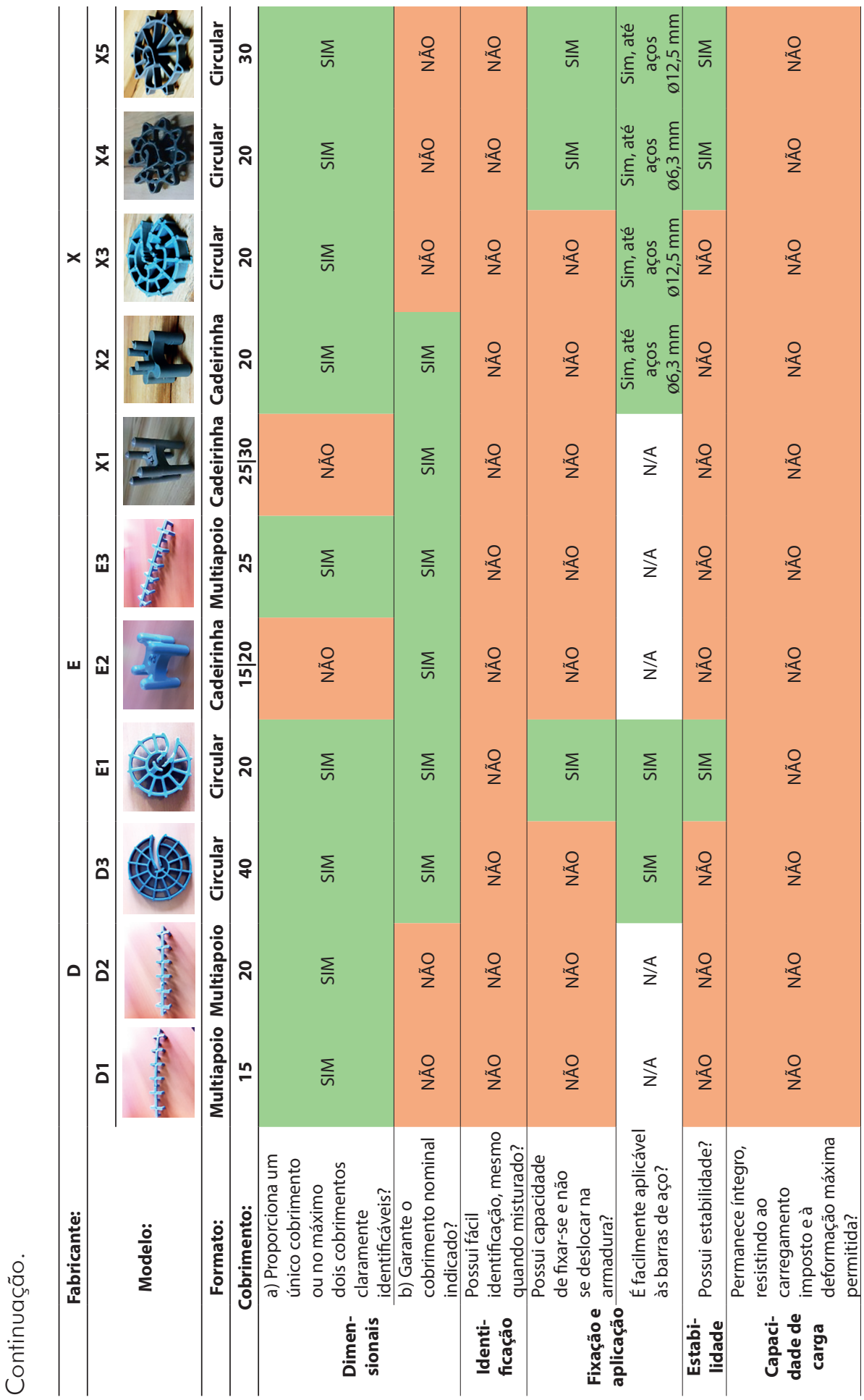


Avaliação de Desempenho de Tecnologias Construtivas Inovadoras:

Conforto Ambiental, Durabilidade e Pós-Ocupação

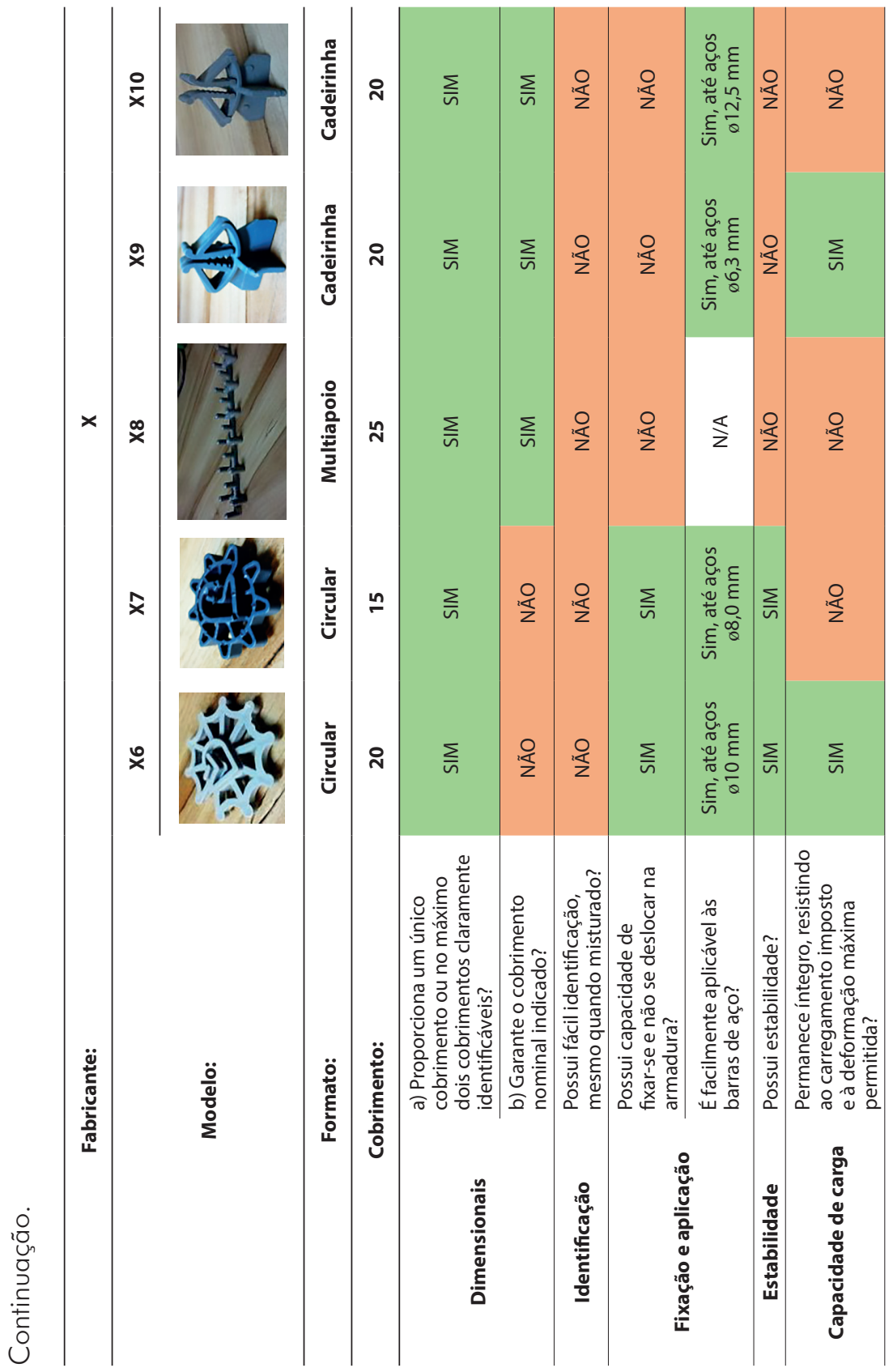




\section{Conclusões}

Os espaçadores plásticos se mostraram um fator contribuinte para a não obtenção do correto cobrimento final, uma vez que este depende diretamente do desempenho daqueles, e nenhum modelo de espaçador avaliado provou-se satisfatório para todos os requisitos e critérios estabelecidos.

Entretanto, ficou claro que todo e qualquer requisito e critério estabelecido pode ser satisfeito, visto que pelo menos um modelo de espaçador foi aprovado em cada avaliação, excetuando-se o requisito de identificação. Este, por sua vez, embora não tenha tido nenhum modelo submetido à avaliação aprovado, conta com peças de fabricantes que não participaram desta pesquisa capazes de satisfazer tal requisito conforme foi exemplificado. Assim sendo, cruzando-se as características dos modelos aprovados em cada requisito, é possível obter um espaçador com desempenho adequado a sua função.

Diante da variedade e diversificação de espaçadores ofertados, assim como o diferente comportamento de cada um, fica comprovada a necessidade de uma norma regulamentadora para esse produto, a fim de balizar a qualidade dos disponíveis no mercado, promovendo um aperfeiçoamento do material, bem como eliminação dos produtos insatisfatórios.

Juntamente com a norma regulamentadora, deve-se exigir certificação e fiscalização de tais produtos por parte dos órgãos responsáveis.

\section{Referências}

ASSOCIAÇÃO BRASILEIRA DE NORMAS TÉCNICAS - ABNT. NBR 6118 : Projeto de estruturas de concreto - Procedimento. Rio de Janeiro, 2014.

ASSOCIAÇÃO BRASILEIRA DE NORMAS TÉCNICAS - ABNT. NBR 14931: Execução de estruturas de concreto - procedimento. Rio de Janeiro, 2004.

ASSOCIAÇÃO BRASILEIRA DE NORMAS TÉCNICAS - ABNT. NBR 15575: Edificaçōes Habitacionais: Desempenho - Parte 1: Requisitos Gerais. Rio de Janeiro, 2013.

BRITISH STANDARDS INSTITUTION - BSI. BS 7973: Spacers and chairs for steel reinforcement and their specification - Part 1: Product performance requirements. UK, 2001. 
CLARK, L.A.; SHAMMAS-TOMA, M.G.K.; SEYMOUR, D.E.; PALLETT, P.F.; MARSH, B.K. How can we get the cover we need? In: The Structure Engineer. Journal of the Institution of Structural Engineers, v. 75, n. 17. UK, 2007.

COMITE EURO-INTERNATIONAL DU BETON - CEB e FÉDÉRATION INTERNATIONALE DE LA PRÉCONTRAINTE - FIP. CEB-FIP Model Code 1990. Design Code. Lausanne: CEB, p. 437, 1993.

MARAN, A.P.; MENNA BARRETO, M.F.F; ROHDEN, A.B.; DAL MOLIN, D.C.C.; MASUERO, J.R. Análise da espessura do cobrimento de armadura em lajes com diferentes distanciamentos entre espaçadores e pontos de amarraçáo. In: Revista IBRACON de Estruturas e Materiais, 2015.

MARSH, B. Specification and achievement of cover to reinforcement. In: Advanced Concrete Technology Set. Volume 1, Pages 1- 9, 2003.

MENNA BARRETO, M.F.F. Avaliaçáo de desempenho de espaçadores plásticos: proposiçáo e avanços de métodos de avaliaçáo. Dissertação (Mestrado) - Universidade Federal do Rio Grande do Sul. Programa de Pós-Graduação em Engenharia Civil, Porto Alegre, 2014.

MERRETZ, W. Achieving concrete cover in construction. In: Concrete in Australia. Technical Feature: Concrete cover., v. 36, n. 1. Austrália, 2010.

MITIDIERI FILHO, C.V.; THOMAZ, E.; VITTORINO, F.; ROCHA, A.L. Sistema de avaliação técnica de novos produtos e sistemas para a construçáo de habitaçôes: uma proposta para o Brasil. Téchne. São Paulo, edição 69, 2002.

SHAW, C.B. Durability of Reinforcement Concrete. 2007. Disponível em: http:// www.localsurveyorsdirect.co.uk/sites/default/files/attachments/reinforced\%20concrete. pdf. Acesso em: maio 2014.

SPEKKINK, D. Performance based design: Bringing Vitruvius up to date. Performance Based Building Thematic Network. Domain 3 Report. Holanda: novembro, 2005.

VAQUERO, J. Separadores para hormigón estructural. Zuncho, n. 13. Septiembre, 2007. 